\title{
Article
}

\section{Tunable Low Crystallinity Carbon Nanotubes/Silicon Schottky Junction Arrays and Their Potential Application for Gas Sensing}

\author{
Alvaro R. Adrian ${ }^{1,2}$, Daniel Cerda ${ }^{1,2}$, Leunam Fernández-Izquierdo ${ }^{3}$, Rodrigo A. Segura ${ }^{4}(\mathbb{D}$, \\ José Antonio García-Merino ${ }^{1,2}$ (1) and Samuel A. Hevia ${ }^{1,2, *}$ \\ 1 Instituto de Física, Pontificia Universidad Católica de Chile, Casilla 306, Santiago 6904411, Chile; \\ aradrian@uc.cl (A.R.A.); ddcerda@uc.cl (D.C.); jose.garcia@uc.cl (J.A.G.-M.) \\ 2 Centro de Investigación en Nanotecnología y Materiales Avanzados, Pontificia Universidad Católica de Chile, \\ Casilla 306, Santiago 6904411, Chile \\ 3 Department of Material Science \& Engineering, The University of Texas at Dallas, Richardson, TX 75080, USA; \\ 1xf180007@utdallas.edu \\ 4 Instituto de Química y Bioquímica, Universidad de Valparaíso, Avenida Gran Bretaña 1111, \\ Valparaíso 2340000, Chile; rodrigo.segura@uv.cl \\ * Correspondence: samuel.hevia@fis.puc.cl; Tel.: +56-999986438
}

\section{check for} updates

Citation: Adrian, A.R.; Cerda, D.; Fernández-Izquierdo, L.; Segura, R.A.; García-Merino, J.A.; Hevia, S.A. Tunable Low Crystallinity Carbon Nanotubes/Silicon Schottky Junction Arrays and Their Potential Application for Gas Sensing. Nanomaterials 2021, 11, 3040. https:// doi.org/10.3390/nano11113040

Academic Editors: Simone Morais and Konstantinos Spyrou

Received: 12 October 2021

Accepted: 4 November 2021

Published: 12 November 2021

Publisher's Note: MDPI stays neutral with regard to jurisdictional claims in published maps and institutional affiliations.

Copyright: (c) 2021 by the authors. Licensee MDPI, Basel, Switzerland. This article is an open access article distributed under the terms and conditions of the Creative Commons Attribution (CC BY) license (https:/ / creativecommons.org/licenses/by/ $4.0 /)$.

\begin{abstract}
Highly ordered nanostructure arrays have attracted wide attention due to their wide range of applicability, particularly in fabricating devices containing scalable and controllable junctions. In this work, highly ordered carbon nanotube (CNT) arrays grown directly on Si substrates were fabricated, and their electronic transport properties as a function of wall thickness were explored. The CNTs were synthesized by chemical vapor deposition inside porous alumina membranes, previously fabricated on n-type Si substrates. The morphology of the CNTs, controlled by the synthesis parameters, was characterized by electron microscopies and Raman spectroscopy, revealing that CNTs exhibit low crystallinity (LC). A study of conductance as a function of temperature indicated that the dominant electric transport mechanism is the $3 \mathrm{D}$ variable range hopping. The electrical transport explored by I-V curves was approached by an equivalent circuit based on a Schottky diode and resistances related to the morphology of the nanotubes. These junction arrays can be applied in several fields, particularly in this work we explored their performance in gas sensing mode and found a fast and reliable resistive response at room temperature in devices containing LC-CNTs with wall thickness between $0.4 \mathrm{~nm}$ and $1.1 \mathrm{~nm}$.
\end{abstract}

Keywords: low crystallinity carbon nanotubes; anodic aluminum oxide; electric transport; gas sensor; Schottky junction arrays

\section{Introduction}

Carbon nanotubes (CNTs) remain being considered as promising materials in science and technology owing to their multiple outstanding properties [1-4]. However, these properties strongly depend on the crystallinity or graphitization level of their walls since this determines the electronic structure [5], and consequently, the optical [6], electric [7], and mechanical [8] properties. These nanostructures have proved to be useful as active materials in photo-actuators [9], photodetectors [10], semiconductor electronics [11], and gas sensors [12]. Nevertheless, it is still challenging to produce an array of CNTs with the same morphological characteristics and, therefore, the same physical properties [13]. A particularly suitable method for growing highly ordered nanotube arrays is to use an anodic aluminum oxide (AAO) as a template. One of the significant advantages of using AAO membranes is the cost-efficient synthesis of large area arrays of densely packed nanopores with well-controlled dimensions in the nanometer range. Also, using this dielectric matrix to deposit the carbon nanostructures provides mechanical support to fabricate robust devices [14]. Using the chemical vapor deposition (CVD) process, the 
diameter, length, wall thickness, and graphitization level of CNT can be controlled [15-18]. The controllability in morphology has an advantage in tuning physical properties $[19,20]$. The use of these arrays has been reported in electronic systems with better performance than those using non-organized CNTs [21,22]. However, the synthesis of millions of CNTs will hardly be completely crystalline, and there will be amorphous components that affect specific properties. Therein lies the importance of studying and classifying the effects of systems with a high degree of disorder.

The distinctive feature that low-crystalline materials exhibit is that they have localized electronic states; therefore, in a material with a strong structural disorder, an electronic structure with highly localized states arises, exhibiting an electric transport mechanism known as variable range hopping (VRH) [23]. In this case, the conductance tends to zero as the temperature tends to zero due to the hopping process is a phonon-assisted mechanism that transfers an electron from one localized state to another [24]. A good description of this mechanism opens the possibility to tailor the global transport properties in arrays with highly structural defects [25]. The contribution to study CNTs with localized states has a relevant impact since macroscopic samples generally contain several distortions, either in the diameters, chirality, or doping [26]. In this case, rather than making an individualized picture of the properties of the nanotubes, it is necessary to generate approximate models of the average characteristics. For that reason, this work analyzes the electric transport in lowcrystallinity CNTs (LC-CNTs) with controllable dimensions in a robust device consisting of Si substrates.

The heterojunction form between carbon allotropes and $\mathrm{Si}$ has been reported as a Schottky junction, in which the carrier transport generally follows the thermionic emission (TE) theory at room temperature [27-29]. Moreover, other conduction mechanisms are superposed in complex nanosystems interfaces such as space-charge limited or tunneling [30]. These components are difficult to explore due to several variables, such as substrate doping, CNTs/Si contact, or temperature [31]. It is important to approach the heterojunction as a global system and isolate the crystalline and non-crystalline components from CNTs. For instance, the study of CNTs and $\mathrm{Si}$ junctions using AAO and CVD process with synthesis temperature of $950^{\circ} \mathrm{C}$ has been reported [31-33]. At this temperature, the CNTs start to lose the defects and behave more as multiwall CNTs with metallic properties [34]. The effects that the impurities in the crystal lattice can induce in electronic transport are not observed in these systems. For that reason, CNTs synthesized at low temperatures are expected to present low crystallinity, and therefore, the effects of interest in the electronic transport mechanism can be observed. Moreover, it is important to analyze the behavior as a function of wall thickness and how this affects the device junction due to dimensionality effects. Furthermore, since these heterojunction devices have been proved to sense gases $[34,35]$, it is appropriate to explore this characteristic in the proposed LC-CNTs. The tunability of electrical transport will allow exploring different morphologies to optimize gas sensing.

This paper presents the synthesis, characterization, and study of the electrical transport properties of LC-CNTs arrays grown directly on Si substrates using AAO as a template. The dominant electric transport mechanism in LC-CNTs is the 3D-VRH and shows a strong dependence on the wall thickness of tubes. Moreover, the LC-CNTs arrays are exposed to reducing gases, and they exhibit a dependence of its electric resistance as a function of gas concentration, which opens the possibilities to use it as gas sensors.

\section{Materials and Methods}

\subsection{Synthesis of Porous Alumina Membranes on Silicon Substrates}

Porous alumina membranes (PAMs) were fabricated on Si substrates using a $5 \mu \mathrm{m}$ layer of $\mathrm{Al}$ (99.999\% purity). The $\mathrm{Al}$ was deposited at a rate of $2 \AA /$ s over polished n-type $\mathrm{Si}(100)$ wafers $(1-10 \Omega \cdot \mathrm{cm})$ by electron beam evaporation. The $\mathrm{Al}$ film was anodized in two steps to obtain PAMs with highly ordered pore patterns [36]. The first anodization step was performed at $40 \mathrm{~V}$ in $0.3 \mathrm{M}$ oxalic acid for a period of $40 \mathrm{~min}$, maintaining the temperature of the electrolyte at $5{ }^{\circ} \mathrm{C}$. Furthermore, an aqueous solution with $6.0 \mathrm{wt} \%$ 
phosphoric acid and $1.8 \mathrm{wt} \%$ chromic acid at $60{ }^{\circ} \mathrm{C}$ was employed to remove the porous alumina layer produced in the first anodization step, leaving an ordered pattern of pores nucleus in the surface of the mask. Then, the second anodization was performed under the same previously mentioned conditions for $50 \mathrm{~min}$, yielding a homogeneous and ordered membrane with a thickness close to $2.5 \mu \mathrm{m}$. Finally, to remove the alumina barrier layer at the bottom of the pores and widen the pores without affecting the membrane order, the samples were subjected to an etching treatment with a $5 \mathrm{wt} \%$ phosphoric acid solution at $21^{\circ} \mathrm{C}$ for $55 \mathrm{~min}$.

\subsection{Low Crystallinity Carbon Nanotubes Synthesis}

The synthesis of LC-CNTs inside the pores of PAMs was achieved by CVD method, using a horizontal tube furnace (MTI - OTF 1200X furnace, MTI Corp., Richmond, CA, USA). A piece of PAM/Si $\left(\sim 1 \mathrm{~cm}^{2}\right)$ was heated at the center of the reactor at a rate of $30^{\circ} \mathrm{C} / \mathrm{min}$ under an Ar atmosphere $(200 \mathrm{sccm})$ until reaching $650{ }^{\circ} \mathrm{C}$. Then, a flow of $\mathrm{C}_{2} \mathrm{H}_{2}$ at $25 \mathrm{sccm}$ was introduced as a carbon source, and CNTs were synthesized at different times: from 1 to $30 \mathrm{~min}$. This process promotes the growth of controllable nanotubes inside the pores with tunable wall thickness by keeping the temperature constant [36]. Finally, the whole system LC-CNTs/PAM/Si was cooled down to $21^{\circ} \mathrm{C}$ under Ar environment.

\subsection{Deposition of the Top Electrode}

Top electrodes, consisting of a $\sim 10 \mathrm{~mm}^{2}$ circular area of $99.9 \%$ pure $\mathrm{Au}$, were deposited perpendicular to the top of the LC-CNT/PAM/Si samples at an evaporation rate of $0.4 \AA$ /s until obtaining $100 \mathrm{~nm}$ of Au thickness. The deposition was performed in a Balzers evaporator equipped with a Temescal STIH-270-2PT (Ferrotec, Livermore, CA, USA) electron beam source operated at $8 \mathrm{kV}$ and a quartz crystal microbalance to measure the evaporation rate and deposited thickness.

\subsection{Characterizations}

The structural characterization was carried out through Raman Spectroscopy using a LabRam010 spectrometer (Horiba. Ltd., Kyoto, Japan) at $632.5 \mathrm{~nm}$ wavelength. Scanning electron microscopy (SEM) and transmission electron microscopy (TEM) were used to characterize the samples morphologically. SEM analysis was carried out using a FEI Quanta 250 FEG (Thermo Fisher Scientific, Waltham, MA, USA). Standard TEM analysis was performed using a Hitachi HT7700 (Hitachi High Tech Co., Ltd., Tokyo, Japan), and high-resolution TEM (HR-TEM) by using a FEI Tecnai ST-F20 microscope (FEI Company, Hillsboro, OR, USA). In order to perform the TEM measurements, CNTs were released from the PAM by dissolving it in sodium hydroxide solution $3.5 \mathrm{M}$ at $21^{\circ} \mathrm{C}$. Afterward, samples were rinsed with double distilled water and suspended in isopropanol alcohol to obtain a CNTs dispersion.

\subsection{Electric Transport Measurements as a Function of Temperature}

The electric transport properties were studied in the samples as a function of the wall thickness by analyzing the I-V curves. This measurement assists in the identification of the existing junction between the Si substrate and the LC-CNTs. The I-V curves were measured in the voltage range from -1.5 to $0.8 \mathrm{~V}$ to predict a model which fits the electrical characteristics of the junction. Moreover, the conductance was measured around zero bias as a function of temperature from 10 to $300 \mathrm{~K}$ to study the dominant transport mechanism. The samples were biased by contacting the top Au-electrode and the Si substrate. The measurements were performed with a Keithley electrometer model 6517B (Keithley Instruments Inc., Cleveland, $\mathrm{OH}, \mathrm{USA}$ ) in a $10 \mathrm{~K}$ closed cycle refrigerator system from Janis Research Company (Wilmington, MA, USA) with high vacuum conditions $\left(<10^{-6}\right.$ Torr). The resistance of the fabricated devices is several orders of magnitude larger than the total resistance of the wires and electrodes; therefore, the errors introduced by using a two-probe measurement are negligible. 


\subsection{Room Temperature Resistance Measurements in Different Atmospheres}

The electrical response of the samples was analyzed in a perturbed atmosphere to test their performances as gas sensors. These were exposed to different cycles of $\mathrm{H}_{2}$ and $\mathrm{C}_{2} \mathrm{H}_{2}$ concentrations under an $\mathrm{Ar}$ atmosphere at room temperature $\left(21 \pm 1{ }^{\circ} \mathrm{C}\right)$, atmospheric pressure, and absence of light. The resistive response (S), shows in Equation (1), is defined as the percentage change in electric resistance when the device is exposed to the analyte $(R(t))$ compared to Ar environment $\left(R_{A r}\right)$. The electric resistance was measured using a Keithley 6487 picoammeter (Tektronix, Portland (Beaverton), OR, USA) around zero bias.

$$
S=\frac{R(t)-R_{A r}}{R_{A r}} 100 \%
$$

The gas mixtures were prepared on the base of a total flow of $100 \mathrm{sccm}$ controlled by Alicat (Alicat Scientific Inc., Tucson, AZ, USA) Mass Flow Controllers (Models MC-5SLM for $\mathrm{Ar}$ and $\mathrm{MC}-10 \mathrm{SCCM}$ for $\mathrm{H}_{2}$ and $\mathrm{C}_{2} \mathrm{H}_{2}$ ). The measured response corresponded to changes in current when the device was exposed to a certain amount of analyte by a certain amount of time.

\section{Results and discussions}

\subsection{Morphological and Structural Characterization}

Figure 1 shows SEM micrographs of a LC-CNTs/PAM/Si sample, synthesized with $5 \mathrm{~min}$. Figure 1a corresponds to a top view of a PAM with the LC-CNTs grown inside, and Figure $1 \mathrm{~b}$ shows the same sample after the Au deposition. The incorporation of the top electrode keeps the pores open, but their average diameter is reduced from $43 \pm 6 \mathrm{~nm}$ to $30 \pm 9 \mathrm{~nm}$. Figure $1 \mathrm{c}$ shows a lateral view of the sample, in which the electrode thickness $(129 \pm 23 \mathrm{~nm})$ and the PAM height $(2040 \pm 2 \mathrm{~nm})$ are determined. Since the Au is deposited with the sample oriented perpendicular to the evaporated metal flow, the Au partially penetrates the nanotubes. Figure $1 \mathrm{~d}$ shows a backscattered electron image which evidences that the Au average penetration inside the pores is about $320 \pm 65 \mathrm{~nm}$. Thus, the Au and Si-electrodes are electrically connected only through the LC-CNTs.
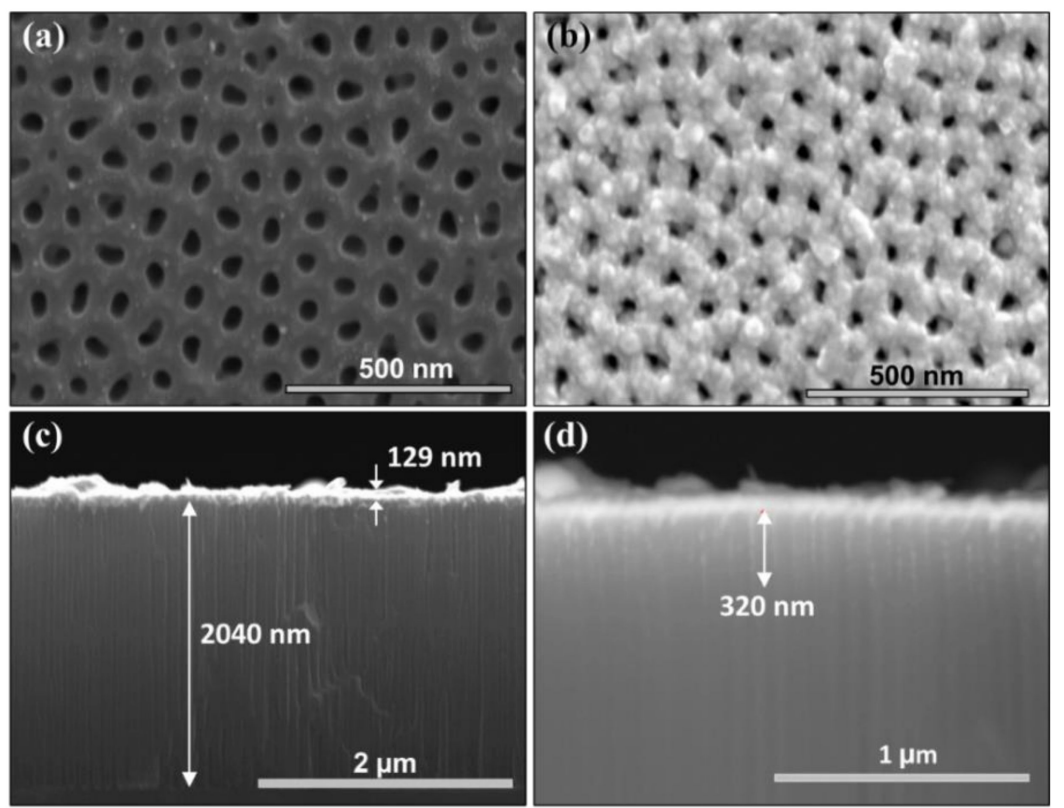

Figure 1. SEM micrographs of a sample synthesized with 5 min of growth time. (a) Top view of the pristine sample. (b) top view after Au deposition. (c) Side view, showing the height of the PAM and the thickness of Au-electrode. (d) Backscattered electron image side view, showing the Au penetration inside the nanopores. 
Figure 2a-c show TEM images of the LC-CNTs grown with 5, 20, and $30 \mathrm{~min}$ of synthesis time, respectively. Moreover, Figure $2 \mathrm{~d}$ corresponds to a representative HR-TEM image of a nanotube synthesized at $30 \mathrm{~min}$. From this image, it is possible to notice the low degree of crystallinity of the CNTs. The average wall thickness of LC-CNTs with $5 \mathrm{~min}$, $20 \mathrm{~min}$, and $30 \mathrm{~min}$ of synthesis time is $0.7 \pm 0.4 \mathrm{~nm}, 1.9 \pm 0.4 \mathrm{~nm}$, and $3.2 \pm 0.4 \mathrm{~nm}$, respectively. These average wall thicknesses are uniform along the vertical direction of the CNTs. The thickness (w) as a function of time synthesis (ts) is plotted in Figure 2e, and a linear dependence is observed.

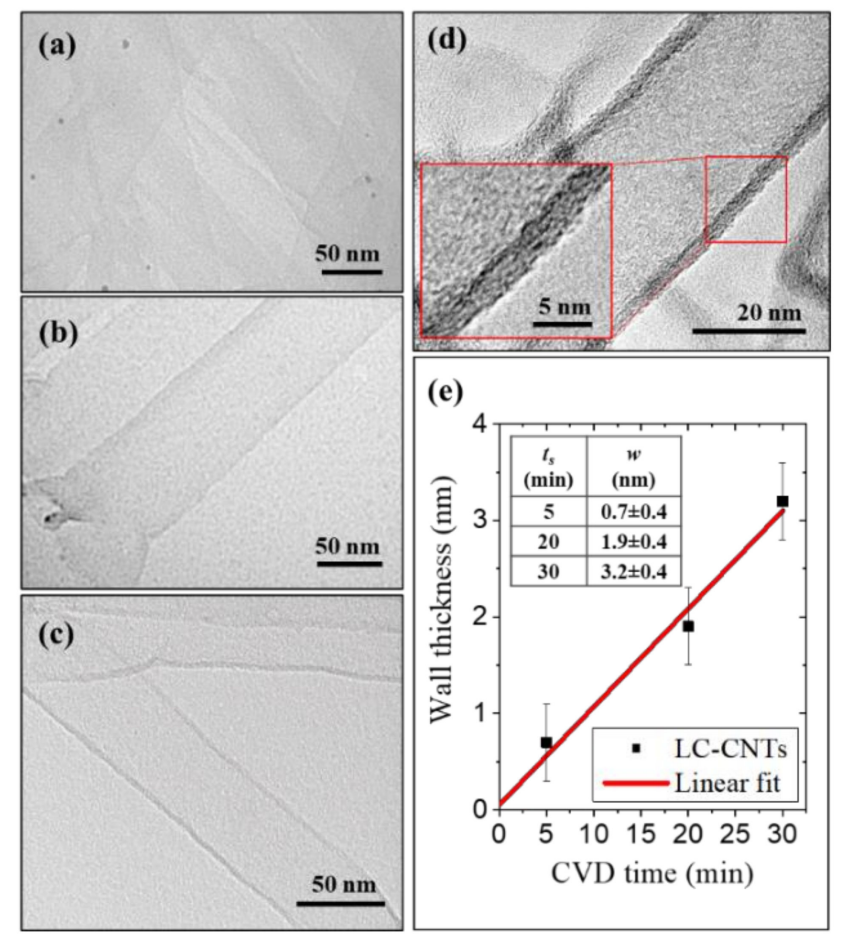

Figure 2. TEM micrographs of LC-CNTs growth with $25 \mathrm{sccm} \mathrm{C}_{2} \mathrm{H}_{2}$ flow at (a) $5 \mathrm{~min}$, (b) $20 \mathrm{~min}$, and (c) 30 min of synthesis time. (d) HR-TEM micrograph of sample growth with $30 \mathrm{~min}$ of synthesis time. (e) Wall thickness as a function of the time synthesis plot obtained from the HR-TEM images.

Figure 3 shows the first-order Raman spectra between $850 \mathrm{~cm}^{-1}$ and $1900 \mathrm{~cm}^{-1}$ range of samples with a wall thickness of $0.7 \mathrm{~nm}, 1.1 \mathrm{~nm}, 1.9 \mathrm{~nm}$, and $3.2 \mathrm{~nm}$. The spectra showed two main resonances located around $1326 \mathrm{~cm}^{-1}$ and $1600 \mathrm{~cm}^{-1}$, which correspond to the $\mathrm{G}$ and $\mathrm{D}$ bands of carbonaceous materials, respectively [37]. Both resonances are linked to vibrational modes of $\mathrm{sp}^{2}$ bonded carbon atoms. The $\mathrm{G}$ peak involves the bond-stretching motion of $C-C$ atoms ( $E_{2 g}$ vibrational mode), which occurs even without the presence of the six-fold aromatic rings [38]. The $\mathrm{D}$ resonance can be linked to an active $\mathrm{A}_{1 \mathrm{~g}}$ breathing mode in amorphous carbon structures [39,40]. In this case, the spectra are characteristic of carbon nanotubes with a low degree of graphitization [37]. Besides, two peaks labeled as $7 \mathrm{~A}_{1}$ and $5 \mathrm{~A}_{1}$ shown in Figure $4 \mathrm{a}$ need to be considered to fit the data. These resonances, located around $1200 \mathrm{~cm}^{-1}$ and $1510 \mathrm{~cm}^{-1}$, can be attributed to the breathing modes of seven and five-member carbon rings, respectively [41].

From the Raman spectra and the plots of fit parameters shown in Figure 3, it is possible to realize that the degree of graphitization of the LC-CNTs does not exhibit significant changes concerning the wall thickness. In all the samples, the Raman shift position of the four resonances, $\operatorname{RS}\left(7 \mathrm{~A}_{1}\right), \mathrm{RS}(\mathrm{D}), \mathrm{RS}\left(5 \mathrm{~A}_{1}\right)$, and $\mathrm{RS}(\mathrm{G})$, is almost constant. Similar behavior is observed for intensity ratios between the peaks, and particularly in the case of $D$ and $G$ peaks, in which the intensity ratio has a value close to 0.9 . On the other hand, the full width at half maximum (FWHM) of G and D peaks (FWHM(G) and FWHM(D)) tend to decrease in a bounded range. These values are an indication that the samples have a similar level 
of graphitization. The low crystallinity of the CNTs observed in TEM micrographs and Raman spectra agree with previous work $[15,22,42]$.

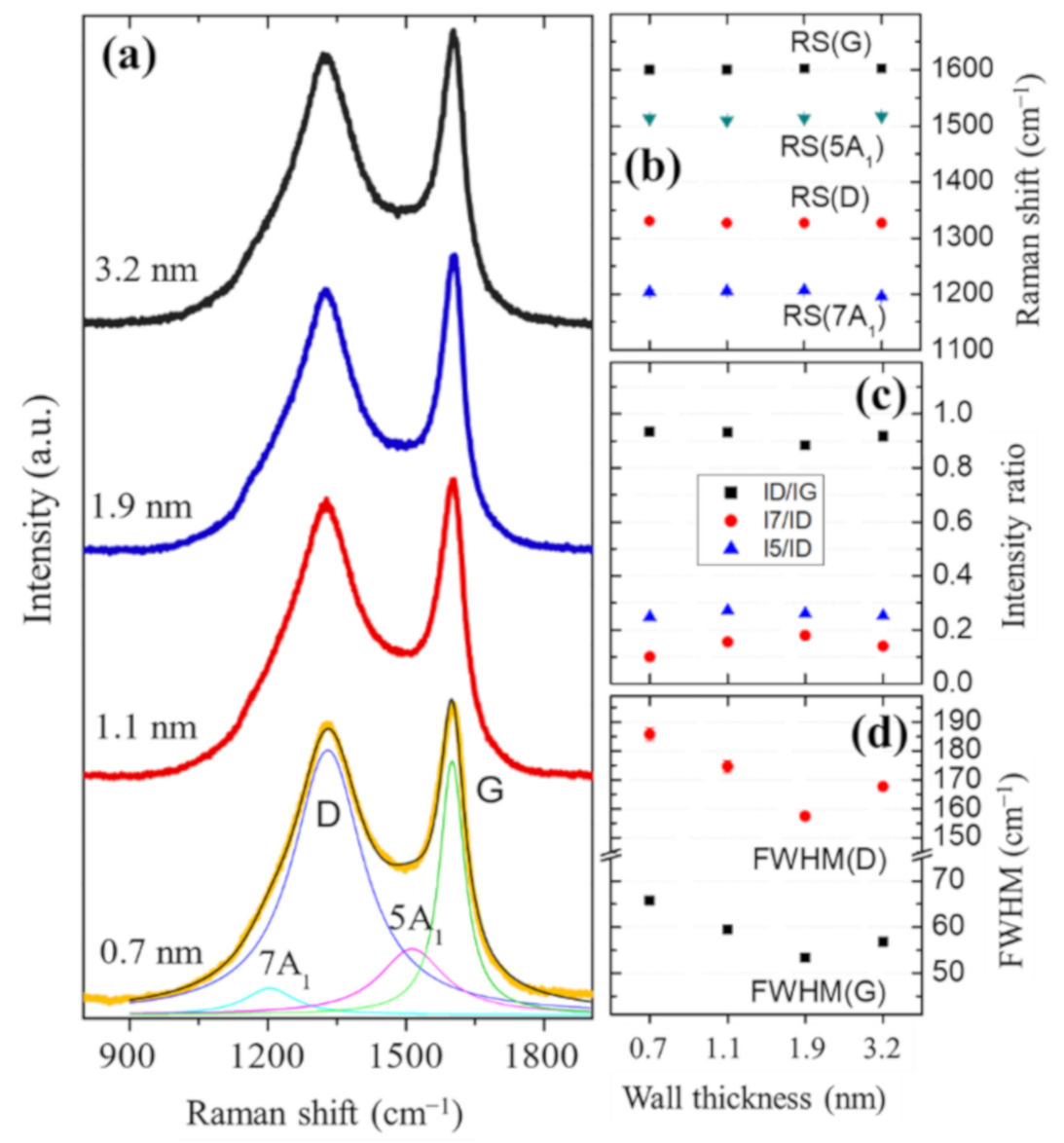

Figure 3. (a) Raman spectra of LC-CNTs as a function of wall thickness. (b) Peak position of resonances $7 A_{1}, D, 5 A_{1}$, G. (c) Representative ratio of $\mathrm{I}(\mathrm{D}) / \mathrm{I}(\mathrm{G}), \mathrm{I}\left(7 \mathrm{~A}_{1}\right) / \mathrm{I}(\mathrm{D})$, and $\mathrm{I}\left(5 \mathrm{~A}_{1}\right) / \mathrm{I}(\mathrm{D})$. (d) FWHM of $G$ and $D$ peaks.

\subsection{Study of Conductance as a Function of Temperature}

Since there is a considerable degree of disorder in the studied CNTs, a conductance analysis as a function of temperature was used to determine their electric transport properties. Figure 4 shows the conductance characterization of the same samples analyzed by Raman spectroscopy. The electrical behavior of all LC-CNTs exhibits a non-metallic temperature dependence, which can be mainly explained by using the variable range hopping (VRH) model [23]. This transport promotes that charge carriers move by phonon-assisted hopping between localized states. The conductance at zero electric fields can be obtained by Mott's law [43] as follows:

$$
G=G_{h} \exp \left[-\left(T_{0} / T\right)^{1 /(d+1)}\right]
$$

where $G_{h}$ is the hopping conductance, $T$ is the absolute temperature, $T_{0}=\alpha^{3} / k_{B} n\left(E_{f}\right)$ is the characteristic activation temperature and is a measure of the degree of electronic localization, which depends on the parameter $\alpha$ that is related to the spatial decay of the localized electronic state, $n\left(E_{f}\right)$, the density of localized electronic states at the Fermi level, and the Boltzmann constant $\left(k_{B}\right)$. The dimensionality value is $d=3$, obtained from the best fit of the data, which indicates that the dominant electric transport mechanism is the three-dimensional variable range hopping (3D-VRH). However, as the LC-CNT wall thickness increase, the conductance does not tend to zero when the temperature tends to zero (see insets in Figure 4), as is required by Equation (2). Hence, it is necessary to 
add a $G_{m}$ parameter that can be considered as roughly independent of temperature, and which represents the main contribution of a metallic transport mechanism acting in parallel to the 3D-VRH for the low-temperature range $(<20 \mathrm{~K})$. It is important to mention that some other transport mechanisms could explain this non-phonon assisted conductivity, such as Bloch Grüneisen [44] or FIT [45]. However, the contribution of $G_{m}$ is at least two orders of magnitude lower than VRH around $300 \mathrm{~K}$, therefore, for simplicity, the model with the fewest free fit parameters was used for the electric conductance curve fitting. The parameters of the fitting of each curve are presented in Table 1 . It is noticed that $T_{0}$ decreases when the wall thickness increases. This value changes up to two orders of magnitude from $0.7 \mathrm{~nm}$ to $3.2 \mathrm{~nm}$ of wall thickness and is in good range for amorphous systems $\left(10^{5}-10^{12} \mathrm{~K}\right)$ [46]. This difference could be originated by an increment in $n\left(E_{f}\right)$ or a reduction of the localized electronic wave function $\alpha$. Nevertheless, the magnitude of this difference is expected to mainly arrive from a change in $\alpha$, due to $T_{0}$ has a cubic dependence on this parameter. The previous discussion implies that the wave functions are less localized as the wall thickness increases, which is also consistent with the observed behavior of the parameter $G_{m}$.

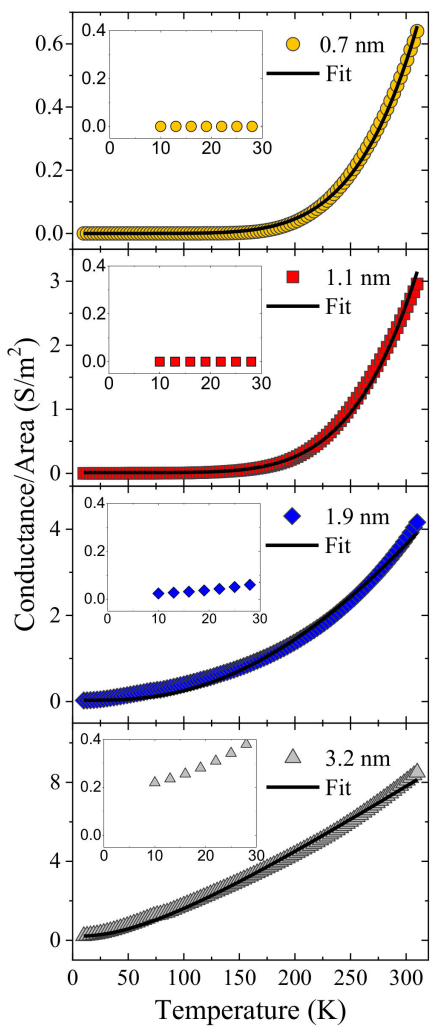

Figure 4. Conductance as a function of temperature and wall thickness of LC-CNTs. Insets show a zoom near $10 \mathrm{~K}$.

Table 1. Fitting parameters for the experimental conductance of Figure 4.

\begin{tabular}{cccc}
\hline $\boldsymbol{w}(\mathbf{n m})$ & $\boldsymbol{T}_{\mathbf{0}}(\mathbf{K})$ & $\boldsymbol{G}_{\boldsymbol{h}}\left(\mathbf{S} / \mathbf{m}^{\mathbf{2}}\right)$ & $\boldsymbol{G}_{\boldsymbol{m}} \mathbf{( S / \mathbf { m } ^ { 2 } )}$ \\
\hline $0.7 \pm 0.4$ & $8.6 \pm 0.2 \times 10^{7}$ & $6.0 \pm 0.9 \times 10^{9}$ & $1.0 \pm 0.1 \times 10^{-4}$ \\
$1.1 \pm 0.4$ & $7.1 \pm 0.2 \times 10^{7}$ & $1.0 \pm 0.1 \times 10^{10}$ & $1.1 \pm 0.1 \times 10^{-2}$ \\
$1.9 \pm 0.4$ & $1.8 \pm 0.1 \times 10^{6}$ & $2.4 \pm 0.3 \times 10^{4}$ & $3.0 \pm 0.3 \times 10^{-2}$ \\
$3.2 \pm 0.4$ & $2.4 \pm 0.1 \times 10^{5}$ & $1.6 \pm 0.1 \times 10^{3}$ & $2.1 \pm 0.2 \times 10^{-2}$ \\
\hline
\end{tabular}

\subsection{Gas Sensing Measurements}

The tunable electric transport exhibited by the nanotubes as a function of wall thickness opens the possibility to design devices for a particular application. For instance, a 
sensor to detect a certain gas atmosphere is feasible since the molecules interacting with the sample are expected to change the electrical parameters [47]. To study this principle, an experiment to measure the electrical resistance was performed in a gas chamber for a set of samples with wall thickness between 0.3 to $3.2 \mathrm{~nm}$. Figure 5a shows the resistive response of a specific device with $0.7 \mathrm{~nm}$ wall thickness under different concentrations of analytes $\left(\mathrm{H}_{2}\right.$ and $\left.\mathrm{C}_{2} \mathrm{H}_{2}\right)$ from $1 \%$ to $5 \%$. It is observed five representative cycles of the transient responses under $\mathrm{H}_{2}$ and $\mathrm{C}_{2} \mathrm{H}_{2}$ analytes. The maximum values reveal a quasi-linear dependence on both gas concentrations (insets), which is an indication that the sensing mechanism is not saturated under these conditions. The resistive response has been tested in different bias voltages, and the results are exposed in Figure 5b. For both analytes, the sample exhibits their maximum response at biased closed to $0.3 \mathrm{~V}$. This nonlinear behavior is consistent with the observed in materials forming junctions in which the maximum sensitivity is related to a potential barrier [48].
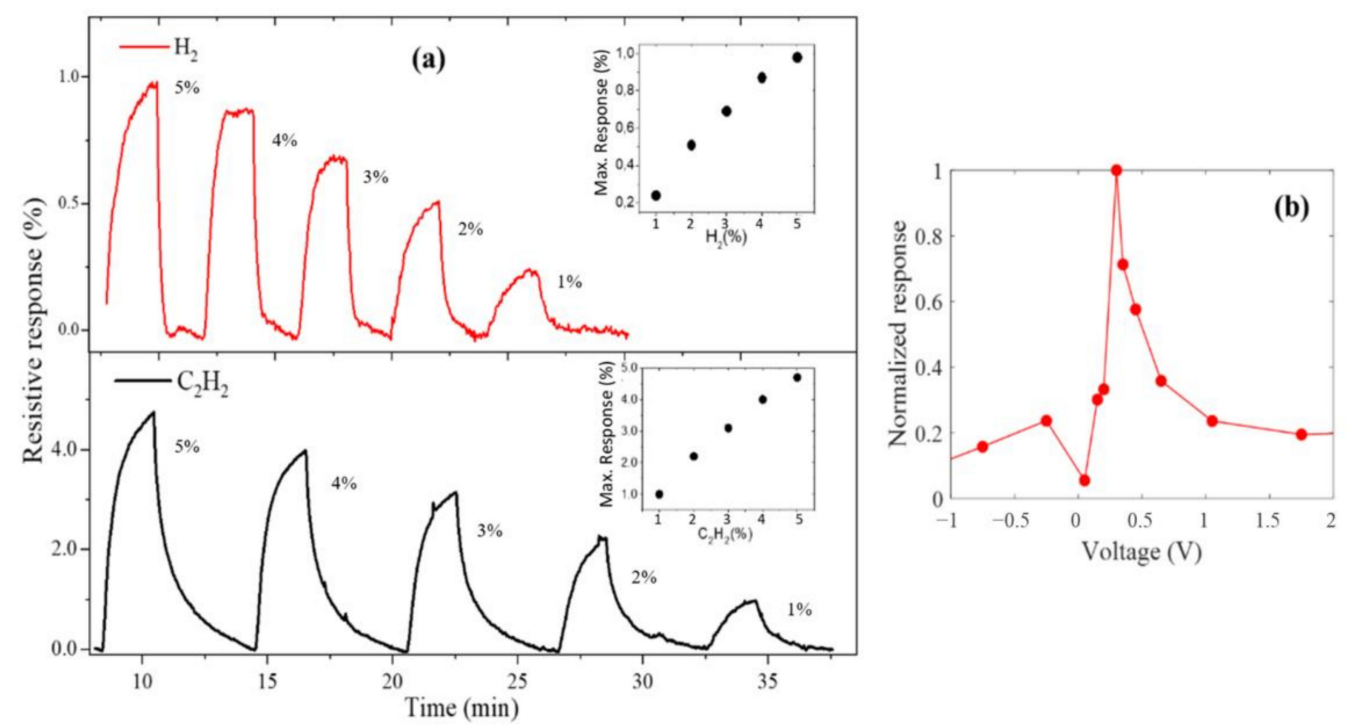

Figure 5. (a) Gas sensing behavior of sample with $0.7 \mathrm{~nm}$ wall thickness at different $\mathrm{H}_{2}$ and $\mathrm{C}_{2} \mathrm{H}_{2}$ concentrations. Insets show the maximum sensitivity percentage as a function of the analyte concentration. (b) Normalized resistive response as a function of bias voltage.

Additionally, the resistive response of several devices was evaluated at the same concentrations of $\mathrm{H}_{2}$ and $\mathrm{C}_{2} \mathrm{H}_{2}$, and a bias voltage around $0.3 \mathrm{~V}$. Particularly, a strong dependence as a function of the wall thicknesses of LC-CNTs was observed. Table 2 summarizes the maximum response measured under $\mathrm{H}_{2}$ and $\mathrm{C}_{2} \mathrm{H}_{2}$, and the conductance at zero bias. Only the devices containing LC-CNTs with wall thicknesses between 0.4 and $1.9 \mathrm{~nm}$ exhibit a response to the presence of the analytes. In the case of devices with thin walls $(<0.4 \mathrm{~nm})$, a high noise was presented in the current measurements; since thinner tubes have a very low conductance (bellow $5 \times 10^{-3} \mathrm{~S} / \mathrm{m}^{2}$ ), the gas sensing signal was overlapped to the noise. Moreover, for tubes with thicker walls $(>1.1 \mathrm{~nm})$ and higher conductance, the sensibility tens to disappear. For both analytes and in all tested concentrations, the response time of the arrays was less than $15 \mathrm{~s}$, a period that can be mainly attributed to the time the analyte takes flowing from the flow controller to the device. The half-maximum time, period which the sensor takes to reach half of the maximum response, was observed between $15 \mathrm{~s}$ and $25 \mathrm{~s}$ for all cases, being just a few seconds faster for $\mathrm{H}_{2}$ than $\mathrm{C}_{2} \mathrm{H}_{2}$.

Previous reports indicate that devices built on the same conditions as these LC-CNTs do not respond electrically to $\mathrm{H}_{2}$ perturbation by a reaction effect [35]. Besides, the results of Figure $5 \mathrm{~b}$ point out that the LC-CNTs/Si samples contain a diode-like junction since the electrical response is more representative around $0.3 \mathrm{~V}$ bias voltage. This effect is common in porous nanomaterials in which the gas produces a perturbation at the junction 
interface that gives rise to a change in the electrical signal [49-52]. The physical mechanism behind this is that the gases permeate through the pores until it reaches the contact barriers, producing the electrical difference. Moreover, we performed the gas sensing experiment in self-supported LC-CNTs (without the Si substrate), using Au electrodes in the top and the bottom, and there was no change in the resistivity response. Thus, the heterojunction is expected to promote the sensing gases mechanism and, to explore its nature, an analysis of the electrical transport is carried out below.

Table 2. Maximum resistive response measuring under exposure to $5 \%$ of $\mathrm{H}_{2}$ and $\mathrm{C}_{2} \mathrm{H}_{2}$ concentration in Ar atmosphere for several LC-CNTs devices.

\begin{tabular}{cccc}
\hline$w(\mathbf{n m})$ & $\mathbf{H}_{\mathbf{2}}$ Max. Resp. (\%) & $\mathbf{C}_{\mathbf{2}} \mathbf{H}_{\mathbf{2}}$ Max. Resp. (\%) & Conductance/Area $\left(\mathbf{S} / \mathbf{m}^{\mathbf{2}}\right)$ \\
\hline $0.3 \pm 0.4$ & 0 & 0 & $2.41 \pm 0.02 \times 10^{-3}$ \\
$0.4 \pm 0.4$ & $2.7 \pm 0.1$ & $5.2 \pm 0.1$ & $1.62 \pm 0.01 \times 10^{-1}$ \\
$0.7 \pm 0.4$ & $1.0 \pm 0.2$ & $5.7 \pm 0.1$ & $1.94 \pm 0.02 \times 10^{-1}$ \\
$1.1 \pm 0.4$ & $0.4 \pm 0.2$ & $1.3 \pm 0.2$ & $2.00 \pm 0.02 \times 10^{0}$ \\
$1.9 \pm 0.4$ & 0 & $2.2 \pm 0.2$ & $2.90 \pm 0.03 \times 10^{0}$ \\
$3.2 \pm 0.4$ & 0 & 0 & $6.83 \pm 0.07 \times 10^{0}$ \\
\hline
\end{tabular}

\subsection{Electrical Characterization of the LC-CNTs/Si Junction}

To explain the previous results, we study the junction between LC-CNTs and $\mathrm{Si}$, with a focus on the devices that exhibit the highest sensitivity. For that purpose, the dark $\mathrm{I}-\mathrm{V}$ curves were measured on samples that contain LC-CNTs with $0.4 \mathrm{~nm}, 0.7 \mathrm{~nm}$, and $1.1 \mathrm{~nm}$ of wall thickness, in a voltage range from $-1.5 \mathrm{~V}$ to $0.7 \mathrm{~V}$ at room temperature, connecting the positive terminal to the LC-CNTs (Au-electrode) and the negative to the $\mathrm{Si}$ substrate. The results are plotted in Figure 6, in which it is observed that the curves exhibit a rectifying behavior with a high reverse current. In fact, these I-V curves can be modeled by an equivalent circuit consisting of a resistance connecting in parallel with a diode and a resistance in series, as shown in the inset of Figure 6.

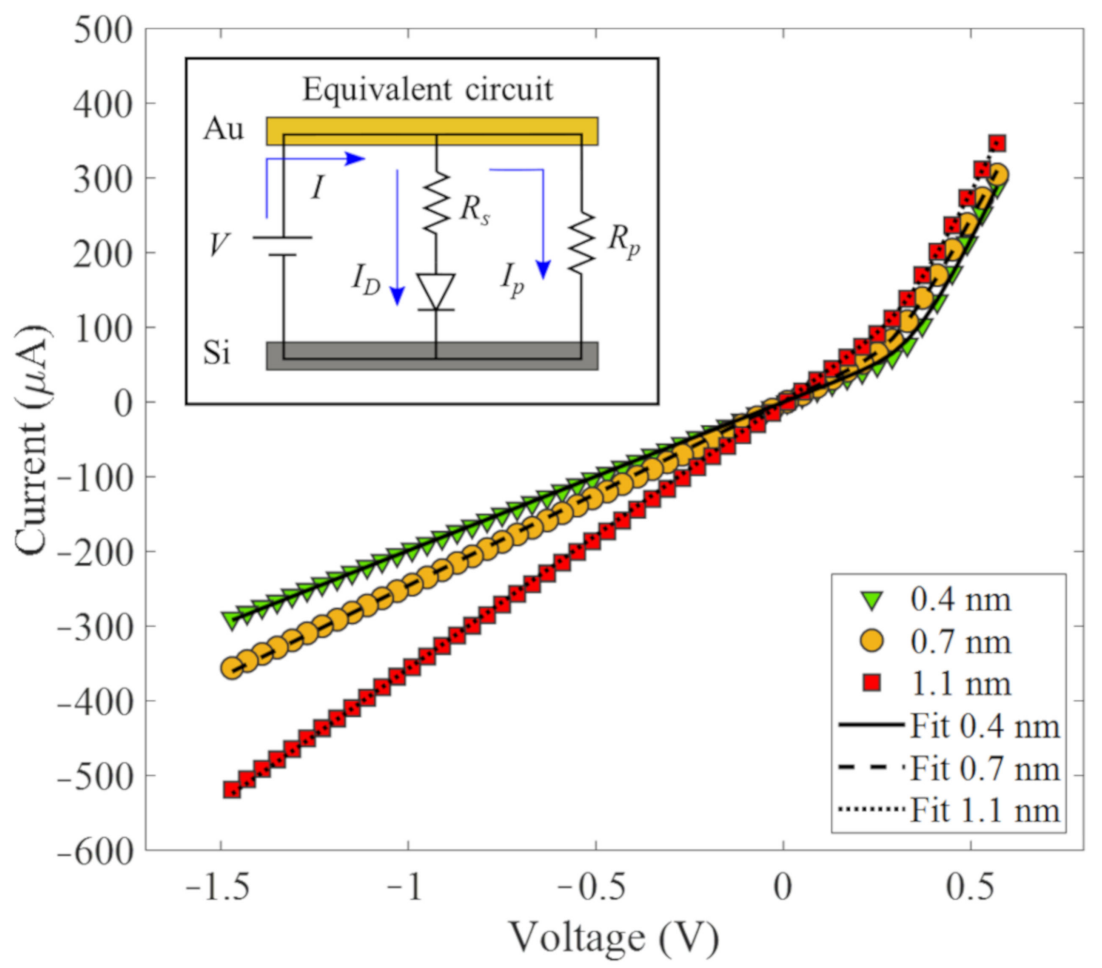

Figure 6. Room temperature dark I-V curves of samples with wall thickness of $0.4 \mathrm{~nm}, 0.7 \mathrm{~nm}$, and $1.1 \mathrm{~nm}$. Equivalent circuit (inset). 
The I-V curves indicate that the arrays present two kinds of junctions attributed to the contacts between LC-CNTs and Si. Since below $0 \mathrm{~V}$, the I-V curves have linear behavior, and above $0 \mathrm{~V}$ has a nonlinear tendance, the simplest model that explains this behavior is a parallel system composed of rectifying (Schottky) and non-rectifying (ohmic) junctions. The resistance in parallel $\left(R_{p}\right)$ of the circuit represents the equivalent resistance of all LC-CNTs ohmic-connected with the substrate. Meanwhile, the resistance in series $\left(R_{S}\right)$ represents the equivalent resistance of the LC-CNTs connected to the Si that forming a rectifying junction. Thus, $R_{S}$ considers the resistance of the LC-CNTs plus the junction resistances. This junction can be modeled as a Schottky barrier [31,53], and the current through the thermionic emission diffusion (TED) theory [54], described by:

$$
I_{D}=I_{S}\left[\exp \left(\frac{V}{n V_{T}}\right)-1\right]
$$

This model initially developed for charge carrier transport across potential barriers in crystalline materials has also been used for non-crystalline systems [49]. Considering the equivalent circuit (inset Figure 6), the total current through it is given by the expression [55]:

$$
I=I_{D}+I_{p}=I_{s}\left[\exp \left(\frac{V\left(1+R_{s} / R_{p}\right)-I R_{s}}{n V_{T}}\right)-1\right]+\frac{V}{R_{p}}
$$

where $I_{D}$ is the current through the diode and $R_{s}, I_{p}$ is the current through $R_{p}, I_{S}$ corresponds to the saturation current, $n$ is the ideality factor, and $V_{T}=k_{B} T$ is the thermal voltage. The analytical solution of this equation can be obtained using the Lambert $W$ function [55].

$$
I=\frac{n V_{T}}{R_{s}} W\left\{\frac{I_{s} R_{s}}{n V_{T}} \exp \left(\frac{V+I_{S} R_{s}}{n V_{T}}\right)\right\}-I_{S}+\frac{V}{R_{p}}
$$

Since the model is dictated by thermionic emission, $I_{S}$ has the following expression:

$$
I_{s}=A \cdot A^{*} \cdot T^{2} \cdot \exp \left(\frac{-\phi_{B}}{V_{T}}\right)
$$

where $A$ is the contact area, $A^{*}$ is the Richardson constant, and $\phi_{B}$ is the barrier voltage.

Table 3 shows the parameters of the I-V curves fitting of Figure 6 and other relevant information calculated from the fit parameters. It is observed that $n$, which is a measure of conformity of the diode behavior to TED theory, has a close value to 1 (ideality), indicating that the model is appropriate to describe the charge transport across the junction. The equivalent resistance $R_{p}$ decreases as the wall of the CNTs widens. This dependence was expected due to his value is related to the individual resistance of the nanotubes, which are less resistive as their wall thickness increases. The value of $R_{S}$ slowly decreases as the wall widens; however, in this case, it is not possible to attribute this only to the resistance of the LC-CNTs due the junction resistances are expected to contribute to the equivalent resistance Rs. However, the values of $R_{s}$ and $R_{p}$ can be used to get a lower bound of the percentage of CNTs connected through a Schottky junction (SC), because $R_{S}$ is an upper bound of the equivalent resistance of the CNTs connected through a Schottky junction but without considering the junction resistance contribution. This percentage is given by $S C=100 /\left(1+R_{S} / R_{p}\right)$, and as we can be observed in Table 3, the number of CNTs connected through a Schottky junction is more than $80 \%$ in all the cases. 
Table 3. Fitted parameters of $\mathrm{I}-\mathrm{V}$ curves as a function of wall thickness.

\begin{tabular}{cccccccc}
\hline $\boldsymbol{w}(\mathbf{n m})$ & $\boldsymbol{n}$ & $\boldsymbol{R}_{\boldsymbol{p}}(\boldsymbol{\Omega})$ & $\boldsymbol{R}_{\boldsymbol{S}}(\boldsymbol{\Omega})$ & $\boldsymbol{I}_{\boldsymbol{S}}(\mathbf{n A})$ & $S C(\%)$ & $\boldsymbol{A}\left(\mathbf{m}^{\mathbf{2}}\right)$ & $\boldsymbol{\phi}_{\boldsymbol{B}}(\mathrm{eV})$ \\
\hline $0.4 \pm 0.4$ & $1.09 \pm 0.01$ & $11226 \pm 171$ & $1093 \pm 16$ & $0.11 \pm 0.18$ & $>91$ & $5.5 \times 10^{-8}$ & $0.34 \pm 0.04$ \\
$0.7 \pm 0.4$ & $1.00 \pm 0.01$ & $5019 \pm 106$ & $1110 \pm 28$ & $0.13 \pm 0.54$ & $>82$ & $9.0 \times 10^{-8}$ & $0.35 \pm 0.11$ \\
$1.1 \pm 0.4$ & $1.05 \pm 0.01$ & $3891 \pm 36$ & $872 \pm 14$ & $0.13 \pm 0.26$ & $>82$ & $1.4 \times 10^{-7}$ & $0.36 \pm 0.05$ \\
\hline
\end{tabular}

From the currents $I_{s}$, whose values are according to the literature [31,56], and based on Equation (6), it is possible to estimate an average barrier voltage $\phi_{B}$ of the junctions. For that, first is necessary to compute the contact area $A$ for each sample. Considering that one nanotube has a cross-sectional area given by the expression $A_{C N T}=w \pi\left(D_{p}-w\right)$, where $w$ is wall thickness, and $D_{p} \approx 50 \mathrm{~nm}$ is the average pore diameter of the bare $\mathrm{AAO}$, is obtain a values of about $6 \times 10^{-17} \mathrm{~m}^{2}, 11 \times 10^{-17} \mathrm{~m}^{2}$, and $17 \times 10^{-17} \mathrm{~m}^{2}$ for samples with $0.4 \mathrm{~nm}, 0.7 \mathrm{~nm}$, and $1.1 \mathrm{~nm}$ wall thickness, respectively. Then, the total number of CNTs connected in each sample is around $1 \times 10^{9}$, since the area of the top electrode is $\sim 10 \mathrm{~mm}^{2}$ and the pores cover about $20 \%$ of the total area of the electrode (determined from an image processing method of a SEM picture of a bare PAM). Finally, the total contact area A of the Schottky junctions can be calculated considering the percentage of the CNTs connected to the Si through this junction. The values for $A$ are shown in Table 3, together with the average barrier voltage $\phi_{B}$, which has values between 0.34 to $0.36 \mathrm{eV}$ for the three samples.

Figure $7 \mathrm{a}-\mathrm{c}$ shows the dark I-V curves as a function of temperature $(20 \mathrm{~K}$ to $300 \mathrm{~K})$ of samples that contain LC-CNTs with a wall thickness of $0.4 \mathrm{~nm}, 0.7 \mathrm{~nm}$, and $1.1 \mathrm{~nm}$, respectively. The three samples exhibit the same behavior: as the temperature decrease, the slope of both sides of the I-V curves decreases, and the region voltage in which the curve experiences the change in the slope moves to a higher voltage. With the model previously discussed, we fit the I-V curves over the full range of temperatures. The conductance $\sigma_{p}=1 / R_{p}$ and $\sigma_{s}=1 / R_{S}$ as a function of temperature are plotted in Figure $7 \mathrm{~d}-\mathrm{f}$ for each sample, and the inserts show the ideality factor and the average barrier voltage $\phi_{B}$. These results are consistent with the hopping conduction of the Equation (2) determined for the LC-CNTs, in which $\sigma_{p}$ tends to zero and represents the conductance through the nanotubes.

Additionally, the ideality factor increases as the temperature drops since the TE mechanism tends to vanish. This behavior is reported for Schottky junctions in the case of tunneling through the contact barrier [57]. Moreover, the rise of $\phi_{B}$ when increasing the temperature in Schottky contacts is related to the temperature-activated charge carriers across the interface. The electrons at low temperatures can surmount the barriers through tunneling, and when the temperature increases, the carriers gain enough energy to reach the higher barrier through thermionic emission. Consequently, the obtained $\phi_{B}$ will raise with the increase in temperature and bias voltage $[58,59]$. These results confirm that the chosen model is satisfactory with the morphology and nature of all samples.

Finally, the existence of Schottky barriers between the LC-CNTs and Si reinforce that the mechanism of gas sensing in the devices is through the permeability of the analytes at the heterojunction. This mechanism is explained to the chemisorption of the analytes on the interface, the layers, or the contact barriers that changes the local density of charge carriers and induces a relatively large difference in the electrical measurements [60-62]. Even though all samples have the same sensing mechanism, there is an optimal CNT morphology in such a way that the conductivity is propitious to transport the charge. For instance, the thinner LC-CNTs have high resistance, and the electrical response cannot be readout. On the other hand, when the tubes have thicker walls, they present lower resistance, and the parallel equivalent circuit suppresses the Schottky contact effect.

Although there are devices with higher gas sensitivity than what is presented here, it is possible to propose the decoration of the internal walls of the LC-CNTs with nanoparticles to enhance their performance [63]. This opens the possibility to adapt the samples in an attractive humidity sensor or multimode analyte analyzer by reading out the electronic response [64]. The highly-order constitution of the nanotubes with perfectly perpendic- 
ular orientation opens the possibility to establish a robust platform to develop on-chip devices [65].
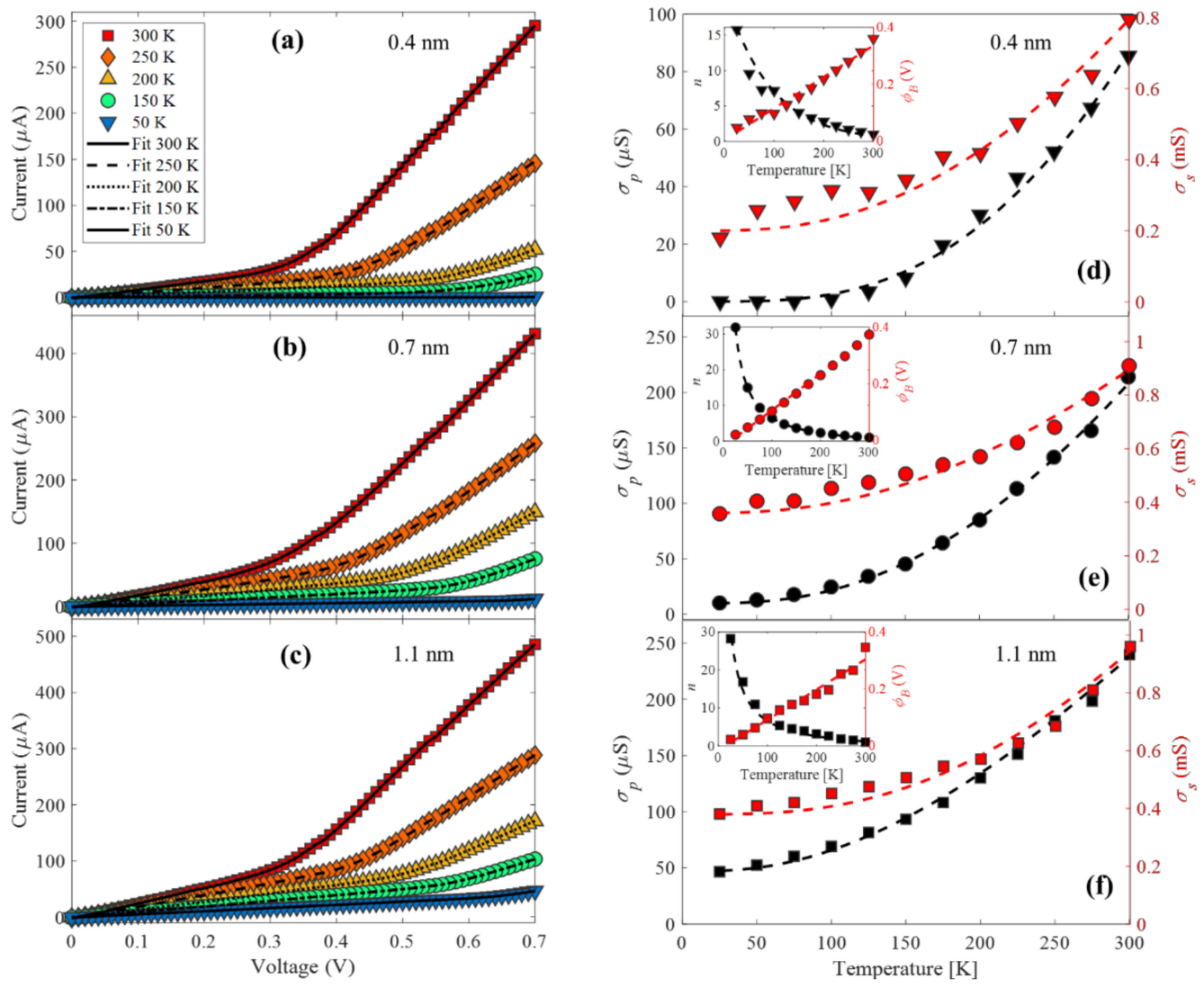

Figure 7. (a-c) I-V curves measured at $300 \mathrm{~K}, 250 \mathrm{~K}, 200 \mathrm{~K}, 150 \mathrm{~K}$, and $50 \mathrm{~K}$ of samples that contain LC-CNTs with $0.4 \mathrm{~nm}, 0.7 \mathrm{~nm}$, and $1.1 \mathrm{~nm}$ of wall thickness, respectively. (d-f) are the plot of the conductance $\sigma_{p}=1 / R_{p}$ and $\sigma_{s}=1 / R_{s}$ as a function of temperature for each sample, the insert shows the ideality factor and the average barrier voltage $\phi_{B}$ as a function of temperature.

\section{Conclusions}

The fabrication of LC-CNTs arrays with controllable dimensions on Si substrates was successfully achieved using PAMs as templates. The low crystallinity of CNTs was established by Raman spectroscopy and HRTEM. This condition was confirmed by the electrical transport characterization, which shows that the CNTs exhibit a localization of electronic states which depend on their wall thickness, causing 3D-VRH to be the dominant electric transport mechanism. As the wall thickness increases, the electronic wave functions are more delocalized and emerge a metallic transport mechanism parallel to the 3D-VRH.

The arrays containing LC-CNTs with wall thickness in the range of 0.4 to $1.1 \mathrm{~nm}$, exhibit a strong dependence of their resistance as a function of $\mathrm{H}_{2}$ and $\mathrm{C}_{2} \mathrm{H}_{2}$ concentrations in an Ar atmosphere. The most representative array was the one containing LC-CNTs with $0.7 \mathrm{~nm}$ wall thickness, and it exhibits a maximum resistive response of $5 \%$ for $\mathrm{C}_{2} \mathrm{H}_{2}$ and $1 \%$ for $\mathrm{H}_{2}$ analytes at $5 \%$ of concentration. This sample shows a fast response in the gas detection (few seconds) and a short recovery time (few minutes). The origin of this sensing response is related to the existence of a Schottky junction between LC-CNTs and Si. This heterojunction seems to be responsible for gases to permeate and disturb the electrical transport in a specific wall thickness range of LC-CNTs. By engineering the junctions, it is possible to optimize the gas sensing response of these arrays. 
Author Contributions: Conceptualization, A.R.A. and S.A.H.; Data curation, D.C.; Formal analysis, D.C. and J.A.G.-M.; Investigation, A.R.A., D.C. and L.F.-I.; Methodology, A.R.A. and S.A.H.; Resources, R.A.S. and S.A.H.; Supervision, R.A.S.; Validation, A.R.A., D.C. and J.A.G.-M.; Writingoriginal draft, A.R.A.; Writing-review \& editing, J.A.G.-M. and S.A.H. All authors have read and agreed to the published version of the manuscript.

Funding: This research was funded by MINECON-Chile through the project Millennium Nucleus MULTIMAT, by the Air Force Office of Scientific Research [FA9550-18-1-0438]; FONDECYT-ANID grant [3190552, 1161614, 1201589], and the Fondequip [EQM150101]; A.R.A. acknowledges a doctoral studies scholarship from CONICYT-ANID.

Conflicts of Interest: The authors declare no conflict of interest.

\section{References}

1. Arvand, M.; Hemmati, S. Magnetic nanoparticles embedded with graphene quantum dots and multiwalled carbon nanotubes as a sensing platform for electrochemical detection of progesterone. Sens. Actuators B Chem. 2017, 238, 346-356. [CrossRef]

2. Marion, S.; Radenovic, A. Towards artificial mechanosensing. Nat. Mater. 2020, 19, 1043-1044. [CrossRef] [PubMed]

3. Osman, A.I.; Farrell, C.; Al-Muhtaseb, A.H.; Harrison, J.; Rooney, D.W. The production and application of carbon nanomaterials from high alkali silicate herbaceous biomass. Sci. Rep. 2020, 10, 2563. [CrossRef] [PubMed]

4. Chen, J.; Han, J. Effect of hydroxylated carbon nanotubes on the thermal and electrical properties of derived epoxy composite materials. Results Phys. 2020, 18, 103246. [CrossRef]

5. Kayang, K.; Nyankson, E.; Efavi, J.; Apalangya, V.; Adetunji, B.; Gebreyesus, G.; Tia, R.; Abavare, E.; Onwona-Agyeman, B.; Yaya, A. A comparative study of the interaction of nickel, titanium, palladium, and gold metals with single-walled carbon nanotubes: A DFT approach. Results Phys. 2019, 12, 2100-2106. [CrossRef]

6. García-Merino, J.A.; Martínez-González, C.L.; Miguel, C.R.T.S.; Trejo-Valdez, M.; Gutiérrez, H.M.; Torres-Torres, C. Magnetoconductivity and magnetically-controlled nonlinear optical transmittance in multi-wall carbon nanotubes. Opt. Express 2016, 24, 19552-19557. [CrossRef]

7. Merino, J.A.G.; Martínez-González, C.; Miguel, C.R.T.S.; Trejo-Valdez, M.; Gutiérrez, H.M.; Torres-Torres, C. Photothermal, photoconductive and nonlinear optical effects induced by nanosecond pulse irradiation in multi-wall carbon nanotubes. Mater. Sci. Eng. B 2015, 194, 27-33. [CrossRef]

8. Cao, G.; Chen, X. The effects of chirality and boundary conditions on the mechanical properties of single-walled carbon nanotubes. Int. J. Solids Struct. 2007, 44, 5447-5465. [CrossRef]

9. Okazaki, D.; Morichika, I.; Arai, H.; Kauppinen, E.; Zhang, Q.; Anisimov, A.; Varjos, I.; Chiashi, S.; Maruyama, S.; Ashihara, S. Ultrafast saturable absorption of large-diameter single-walled carbon nanotubes for passive mode locking in the mid-infrared. Opt. Express 2020, 28, 19997-20006. [CrossRef]

10. Kumar, R.; Khan, M.A.; Anupama, A.; Krupanidhi, S.B.; Sahoo, B. Infrared photodetectors based on multiwalled carbon nanotubes: Insights into the effect of nitrogen doping. Appl. Surf. Sci. 2021, 538, 148187. [CrossRef]

11. Peng, L.-M.; Zhang, Z.; Wang, S. Carbon nanotube electronics: Recent advances. Mater. Today 2014, 17, 433-442. [CrossRef]

12. Jung, D.; Han, M.; Lee, G.S. Fast-Response Room Temperature Hydrogen Gas Sensors Using Platinum-Coated Spin-Capable Carbon Nanotubes. ACS Appl. Mater. Interfaces 2015, 7, 3050-3057. [CrossRef]

13. Das, D.; Roy, A. Synthesis of diameter controlled multiwall carbon nanotubes by microwave plasma-CVD on low-temperature and chemically processed Fe nanoparticle catalysts. Appl. Surf. Sci. 2020, 515, 146043. [CrossRef]

14. Pan, H.; Gao, H.; Lim, S.; Feng, Y.; Lin, J. Highly Ordered Carbon Nanotubes Based on Porous Aluminum Oxide: Fabrication and Mechanism. J. Nanosci. Nanotechnol. 2005, 5, 277-281. [CrossRef]

15. Segura, R.A.; Contreras, C.; Henriquez, R.; Häberle, P.; Acuña, J.J.S.; Adrian, A.; Alvarez, P.; A Hevia, S. Gold nanoparticles grown inside carbon nanotubes: Synthesis and electrical transport measurements. Nanoscale Res. Lett. 2014, 9, 207. [CrossRef]

16. Ciambelli, P.; Arurault, L.; Sarno, M.; Fontorbes, S.; Leone, C.; Datas, L.; Sannino, D.; Lenormand, P.; Plouy, S.L.B.D. Controlled growth of CNT in mesoporous AAO through optimized conditions for membrane preparation and CVD operation. Nanotechnology 2011, 22, 265613. [CrossRef]

17. Sacco, L.; Florea, I.; Châtelet, M.; Cojocaru, C.-S. Electrical and morphological behavior of carbon nanotubes synthesized within porous anodic alumina templates. J. Phys. Mater. 2018, 1, 015004. [CrossRef]

18. Hou, P.-X.; Yu, W.-J.; Shi, C.; Zhang, L.-L.; Liu, C.; Tian, X.-J.; Dong, Z.-L.; Cheng, H.-M. Template synthesis of ultra-thin and short carbon nanotubes with two open ends. J. Mater. Chem. 2012, 22, 15221-15226. [CrossRef]

19. Fleming, E.; Du, F.; Ou, E.; Dai, L.; Shi, L. Thermal conductivity of carbon nanotubes grown by catalyst-free chemical vapor deposition in nanopores. Carbon 2019, 145, 195-200. [CrossRef]

20. Chen, G.; Futaba, D.N.; Sakurai, S.; Yumura, M.; Hata, K. Interplay of wall number and diameter on the electrical conductivity of carbon nanotube thin films. Carbon 2014, 67, 318-325. [CrossRef]

21. Sohn, J.I.; Kim, Y.-S.; Nam, C.; Cho, B.K.; Seong, T.-Y.; Lee, S. Fabrication of high-density arrays of individually isolated nanocapacitors using anodic aluminum oxide templates and carbon nanotubes. Appl. Phys. Lett. 2005, 87, 123115. [CrossRef] 
22. Hevia, S.A.; Segura, R.; Häberle, P. Low energy electrons focused by the image charge interaction in carbon nanotubes. Carbon 2014, 80, 50-58. [CrossRef]

23. Mott, N.F. Conduction in non-crystalline materials. Philos. Mag. 1969, 19, 835-852. [CrossRef]

24. Edwards, P.; Kuznetsov, V.; Slocombe, D.; Vijayaraghavan, R. The Electronic Structure and Properties of Solids. In Comprehensive Inorganic Chemistry II, 2nd ed.; Reedikj, J., Poeppelmeier, K., Eds.; Elsevier: Amsterdam, The Netherlands, 2013 ; pp. 153-176.

25. Qiu, H.; Xu, T.; Wang, Z.; Ren, W.; Nan, H.; Ni, Z.; Chen, Q.; Yuan, S.; Miao, F.; Song, F.; et al. Hopping transport through defect-induced localized states in molybdenum disulphide. Nat. Commun. 2013, 4, 2642. [CrossRef]

26. Pichler, T.; Knupfer, M.; Golden, M.S.; Fink, J.; Rinzler, A.; Smalley, R.E. Localized and Delocalized Electronic States in Single-Wall Carbon Nanotubes. Phys. Rev. Lett. 1998, 80, 4729-4732. [CrossRef]

27. Filatzikioti, A.; Glezos, N.; Kantarelou, V.; Kyriakis, A.; Pilatos, G.; Romanos, G.; Speliotis, T.; Stathopoulou, D. Carbon nanotube Schottky type photodetectors for UV applications. Solid State Electron. 2019, 151, 27-35. [CrossRef]

28. Mohammed, M.; Li, Z.; Cui, J.; Chen, T.-P. Junction investigation of graphene/silicon Schottky diodes. Nanoscale Res. Lett. 2012, 7, 302. [CrossRef]

29. Tomer, D.; Rajput, S.; Hudy, L.J.; Li, C.H.; Li, L. Carrier transport in reverse-biased graphene/semiconductor Schottky junctions. Appl. Phys. Lett. 2015, 106, 173510. [CrossRef]

30. Guruprasad, K.; Marappan, G.; Elangovan, S.; Jayaraman, S.V.; Bharathi, K.K.; Venugopal, G.; Di Natale, C.; Sivalingam, Y. Electrical transport properties and impedance analysis of $\mathrm{Au} / \mathrm{ZnO}$ nanorods/ITO heterojunction device. Nano Express 2020, 1, 030020. [CrossRef]

31. Kuo, T.-F.; Tzolov, M.B.; Straus, D.A.; Xu, J. Electron transport characteristics of the carbon nanotubes/Si heterodimensional heterostructure. Appl. Phys. Lett. 2008, 92, 212107. [CrossRef]

32. Kuo, T.-F.; Xu, J. Controlled direct growth of vertical and highly-ordered 'carbon nanotube silicon' heterojunction array. MRS Proc. 2005, 901. [CrossRef]

33. Tzolov, M.; Chang, B.; Yin, A.; Straus, D.; Xu, J.M.; Brown, G. Electronic Transport in a Controllably Grown Carbon NanotubeSilicon Heterojunction Array. Phys. Rev. Lett. 2004, 92, 075505. [CrossRef]

34. Hoa, N.D.; Van Quy, N.; Cho, Y.; Kim, D. An ammonia gas sensor based on non-catalytically synthesized carbon. Sens. Actuators B 2007, 127, 447-454. [CrossRef]

35. Ding, D.; Chen, Z.; Rajaputra, S.; Singh, V. Hydrogen sensors based on aligned carbon nanotubes in an anodic aluminum oxide template with palladium as a top electrode. Sens. Actuators B 2007, 124, 12-17. [CrossRef]

36. Hevia, S.; Homm, P.; Cortes, A.; Núñez, V.; Contreras, C.; Ver, J.; Segura, R. Selective growth of palladium and titanium dioxide nanostructures inside carbon nanotube membranes. Nanoscale Res. Lett. 2012, 7, 342. [CrossRef]

37. Segura, R.A.; Hevia, S.; Häberle, P. Growth of carbon nanostructures using a Pd-based catalyst. J. Nanosci. Nanotechnol. 2011, 11, 10036-10046. [CrossRef]

38. Ferrari, A.C.; Robertson, J. Interpretation of Raman spectra of disordered and amorphous carbon. Phys. Rev. B 2000, 61, 14095-14107. [CrossRef]

39. Mapelli, C.; Castiglioni, C.; Zerbi, G.; Müllen, K. Common force field for graphite and polycyclic aromatic hydrocarbons. Phys. Rev. B 1999, 60, 12710-12725. [CrossRef]

40. Castiglioni, C.; Negri, F.; Rigolio, M.; Zerbi, G. Raman activation in disordered graphites of the A' symmetry forbidden $\mathrm{k} \neq 0$ phonon: The origin of the D line. J. Chem. Phys. 2001, 115, 3769-3778. [CrossRef]

41. Doyle, T.E.; Dennison, J.R. Vibrational dynamics and structure of graphitic amorphous carbon modeled using an embedded-ring approach. Phys. Rev. B 1995, 51, 196. [CrossRef]

42. García-Merino, J.; Fernández-Izquierdo, L.; Villarroel, R.; Hevia, S. Photo-thermionic emission and photocurrent dynamics in low crystallinity carbon nanotubes. J. Materiomics 2021, 7, 271-280. [CrossRef]

43. Mott, N.F.; Davis, E.A. Electronic Processes in Non-Crystalline Materials, 2nd ed.; Oxford University Press: New York, NY, USA, 1979.

44. Efetov, D.; Kim, P. Controlling Electron-Phonon Interactions in Graphene at Ultrahigh Carrier Densities. Phys. Rev. Lett. 2010, 105, 256805. [CrossRef]

45. De Nicola, F.; Salvato, M.; Cirillo, C.; Crivellari, M.; Boscardin, M.; Scarselli, M.; Nanni, F.; Cacciotti, I.; De Crescenzi, M.; Castrucci, P. Record efficiency of air-stable multi-walled carbon nanotube/silicon solar cells. Carbon 2016, 101, 226-234. [CrossRef]

46. Halim, J.; Moon, E.J.; Eklund, P.; Rosen, J.; Barsoum, M.W.; Ouisse, T. Variable range hopping and thermally activated transport in molybdenum-based MXenes. Phys. Rev. B 2018, 98, 104202. [CrossRef]

47. Zandi, A.; Gilani, A.; Fard, H.G.; Koohsorkhi, J. An optimized resistive CNT-based gas sensor with a novel configuration by top electrical contact. Diam. Relat. Mater. 2019, 93, 224-232. [CrossRef]

48. Bag, A.; Lee, N.-E. Gas sensing with heterostructures based on two-dimensional nanostructured materials: A review. J. Mater. Chem. C 2019, 7, 13367-13383. [CrossRef]

49. Potje-Kamloth, K. Semiconductor Junction Gas Sensors. Chem. Rev. 2008, 108, 367-399. [CrossRef] [PubMed]

50. Ling, Z.; Leach, C.; Freer, R. Heterojunction gas sensors for environmental $\mathrm{NO}_{2}$ and $\mathrm{CO}_{2}$ monitoring. J. Eur. Ceram. Soc. 2001, 21, 1977-1980. [CrossRef]

51. Mirzaei, A.; Hashemi, B.; Janghorban, K. $\alpha-\mathrm{Fe}_{2} \mathrm{O}_{3}$ based nanomaterials as gas sensors. J. Mater. Sci. Mater. Electron. 2016, 27, 3109-3144. [CrossRef] 
52. Kumar, M.; Bhati, V.S.; Kumar, M. Effect of Schottky barrier height on hydrogen gas sensitivity of metal/TiO 2 nanoplates. Int. J. Hydrogen Energy 2017, 42, 22082-22089. [CrossRef]

53. Uchino, T.; Shimpo, F.; Kawashima, T.; Ayre, G.N.; Smith, D.C.; De Groot, C.H.; Ashburn, P. Electrical transport properties of isolated carbon nanotube/Si heterojunction Schottky diodes. Appl. Phys. Lett. 2013, 103, 193111. [CrossRef]

54. Rezeq, M.; Ali, A.; Patole, S.; Eledlebi, K.; Dey, R.K.; Cui, B. The dependence of Schottky junction (I-V) characteristics on the metal probe size in nano metal-semiconductor contacts. AIP Adv. 2018, 8, 055122. [CrossRef]

55. Ortiz-Conde, A.; García Sánchez, F.J.; Muci, J. Exact analytical solutions of the forward non-ideal diode equation with series and shunt parasitic resistances. Solid-State Electron. 2000, 44, 1861-1864. [CrossRef]

56. Sze, S.M.; Ng, K.K. Physics of Semiconductor Devices; John Wiley \& Sons: Hoboken, NJ, USA, 2007.

57. Verschraegen, J.; Burgelman, M.; Penndorf, J. Temperature dependence of the diode ideality factor in CuInS2-on-Cu-tape solar cells. Thin Solid Film. 2005, 480-481, 307-311. [CrossRef]

58. Li, H.; He, D.; Zhou, Q.; Mao, P.; Cao, J.; Ding, L.; Wang, J. Temperature-dependent Schottky barrier in high-performance organic solar cells. Sci. Rep. 2017, 7, 40134. [CrossRef]

59. Mayimele, M.A.; Diale, M.; Mtangi, W.; Auret, F.D. Temperature-dependent current-voltage characteristics of Pd/ZnO Schottky barrier diodes and the determination. Mater. Sci. Semicond. Process. 2015, 34, 359-364. [CrossRef]

60. Triet, N.M.; Duy, L.T.; Hwang, B.-U.; Hanif, A.; Siddiqui, S.; Park, K.-H.; Cho, C.-Y.; Lee, N.-E. High-Performance Schottky Diode Gas Sensor Based on the Heterojunction of Three-Dimensional Nanohybrids of Reduced Graphene Oxide-Vertical ZnO Nanorods on an AlGaN/GaN Layer. ACS Appl. Mater. Interfaces 2017, 9, 30722-30732. [CrossRef]

61. Biswas, R.U.D.; Oh, W.-C. Comparative study on gas sensing by a Schottky diode electrode prepared with graphenesemiconductor-polymer nanocomposites. RSC Adv. 2019, 9, 11484-11492. [CrossRef]

62. Schierbaum, K.; Kirner, U.; Geiger, J.; Göpel, W. Schottky-barrier and conductivity gas sensors based upon $\mathrm{Pd} / \mathrm{SnO} 2$ and $\mathrm{Pt} / \mathrm{TiO} 2$. Sens. Actuators B 1991, 4, 87-94. [CrossRef]

63. Casanova-Cháfer, J.; Navarrete, E.; Noirfalise, X.; Umek, P.; Bittencourt, C.; Llobet, E. Gas Sensing with Iridium Oxide Nanoparticle Decorated Carbon Nanotubes. Sensors 2018, 19, 113. [CrossRef]

64. Kim, H.-S.; Kim, J.H.; Park, S.-Y.; Kang, J.-H.; Kim, S.-J.; Choi, Y.-B.; Shin, U.S. Carbon nanotubes immobilized on gold electrode as an electrochemical humidity sensor. Sens. Actuators B 2018, 300, 127049. [CrossRef]

65. Hung, C.M.; Le, D.T.T.; Van Hieu, N. On-chip growth of semiconductor metal oxide nanowires for gas sensors: A review. J. Sci. Adv. Mater. Devices 2017, 2, 263-285. [CrossRef] 